\title{
Responses in chemical traits and biomass allocation of Arundo donax L. to deficit resources in the establishment year
}

\author{
Antonio Pompeiano $^{1 *}$, Lorenzo Guglielminetti ${ }^{1}$, Enrica Bargiacchi $^{2}$, and Sergio Miele ${ }^{1}$
}

\begin{abstract}
A large expansion in renewable energy production is underway with an increasing focus on sustainable second-generation biofuels. Fast growing rhizomatous perennial grasses are leading candidates for lignocellulosic feedstock thanks to their positive energy balance, and low ecological/agro-management demands. Biomass accumulation is favored by the efficient use of available resources. The aim of this study was to identify which accumulation processes were most affected in the establishment year of a giant reed (Arundo donax L.) field crop grown under water and $\mathrm{N}$ deficiencies. The relative plasticity of growth of A. donax in response to various levels of resource availability was evaluated. A field scale experiment was carried out, and treatments were arranged as a randomized complete block, strip-plot design with irrigation treatments as the main plot factor and pre-planting $\mathrm{N}$ rate as the sub-plot factor. Biometric relationships between variables were assessed to understand how agro-management factors influence the above ground biomass of giant reed, as well as yield over time. Evidence is presented indicating that growth is strongly enhanced by water availability (+97\% dry weight biomass). Changes in composition were not significant within or among fixed treatments, rather changes were observed over time. A high content of glucans and xylans were detected from early stage, and as the mobilization of minerals increased, lignin content significantly increased as well (from $12 \%$ to $36 \% \mathrm{w} / \mathrm{w}$ ). These results suggest that an increase in the growth of $A$. donax in the establishment year is accomplished by a limited use of the water input.
\end{abstract}

Key words: Biomass allocation, chemical composition, establishment, giant reed, resource use efficiency.

\section{INTRODUCTION}

Arundo donax L. (Poaceae), giant reed, is a perennial rhizomatous grass native to Eurasia that is present in an area ranging from the Mediterranean basin to subtropical wetlands, and up to an altitude of $900 \mathrm{~m}$ a.s.l. This plant is a hardy mesophyte that can adapt to become either a hydrophyte or a xerophyte. It can tolerate a wide range of soils - from heavy clays to loose sands, though it does best in drained soils in riparian habitats, forming monospecific stands (Boose and Holt, 1999). Giant reed uses the $\mathrm{C}_{3}$ pathway for carbon assimilation, and has a high photosynthetic capacity (up to $36.7 \mu \mathrm{mol} \mathrm{CO}_{2} \mathrm{~m}^{-2} \mathrm{~s}^{-1}$ ) associated with the absence of light saturation. Diurnal changes in leaf water potential do not significantly have repercussions on leaf conductance or on $\mathrm{CO}_{2}$ uptake (Rossa et al., 1998).

This monocotyledonous plant is a leading candidate

${ }^{1}$ Università di Pisa, Dipartimento di Scienze Agrarie, Alimentari e Agro-ambientali, Via mariscoglio 34 56124, Pisa, Italia.

*Corresponding author (onaiepmop@gmail.com).

${ }^{2}$ Consorzio Interuniversitario Nazionale per la Scienza e Tecnologia dei Materiali INSTM, Via G. Giusti, 9 50121, Firenze, Italia.

Received: 15 January 2013.

Accepted: 7 August 2013.

doi:10.4067/S0718-58392013000400008 as a lignocellulosic feedstock due to its positive energy balance, high yield potential and the quality of its biomass. It can grow in a considerable variety of habitats, from drought prone areas to high salinity soils, as well as soil contaminated with heavy metals. It requires minimal agronomical intervention and management (Lewandowski et al., 2003). Giant reed cultivation is characterized by a large amount of residue and requires little tillage. It accumulates a large amount of root biomass in deep soil horizons but maintains constant water capture capacities along root profiles (Monti and Zatta, 2009). When compared to annual species or natural grasses, its use in crop rotation performs better in terms of organic matter improvement and microbial biomass (Riffaldi et al., 2010).

High growth rate, efficient resource usage, optimized leaf architecture, and the ability to colonize the soil with its extensive and persistent underground rhizomatous system, are some of the feature that enable giant reed to out-compete native species. An ideal non-food feedstock shares common traits with invasive plants and as such, non-native species should be introduced to a new area in accordance with a weed risk-assessment protocol specific for each genotype-environment combination (Barney and Ditomaso, 2008) in addition to following local regulations (Mack, 2008). Fast-growing rhizomatous perennials are widely used as filters for wastewater 
treatment and differences in biomass allocation patterns determine their efficiency for nutrient removal. Perennial rhizomatous grasses allocate a high proportion of biomass into rhizomes, which represent major sink for accumulated nutrients. The enhanced plant growth that generally accompanies greater nutrient input is often accompanied by shifts in biomass partitioning. It is often (but not always) true, that in the case that vigorous plant growth, biomass partitioning favors the flux of biomass preferentially to below-ground organs.

Nitrogen, often regarded as the single most important nutrient, has been shown to affect radiation-use efficiency (Muchow and Davis, 1988). In an agricultural context, the application and use efficiency of water and $\mathrm{N}$ are mostly studied from a yield and quality oriented perspective. There is increasing evidence that perennial cropping systems can use resources more efficiently than the annual ones (Jordan et al., 2007), though direct quantitative and qualitative comparisons are difficult to make due to intrinsic differences in growth period.

The favorable chemical and physical properties of lignocellulosic biomass to be used in ethanol production have long been known. Conversely, little attention has been given neither to determining the best quality biomass for bio-refinery applications nor to developing agronomic practices aimed at obtaining the best type of biomass for this industry. In particular, field-scale studies in this area are lacking. Recently, a study conducted on switch grass showed that hexose and pentose sugars vary over time (Schmer et al., 2012). Yet cellulosic refineries operate continuously, and seasonal variation in biomass composition would impact ethanol conversion rates. The partitioning of biomass between above- and belowground organs in response to resource availability is another area of study that has not received much attention. In giant reed, little information is available on how nutritional inputs interact and affect growth patterns and biomass partitioning. The objectives of this study were (i) to determine the underlying morphometric parameters associated with above-ground dry biomass, (ii) to evaluate the effects of $\mathrm{N}$ fertilization, supplemental irrigation, and their interaction on the development of above-and belowground components, and (iii) to determine the drivers of variations in biomass quality at different maturity stages.

\section{MATERIALS AND METHODS}

\section{Experimental conditions}

A field-scale study was conducted in 2011 on a relatively flat and well-drained field in a commercial farm located

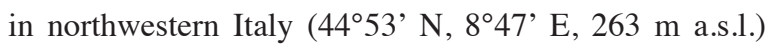
The region has a Mediterranean climate, with cool wet winters and warm dry summers. The soil has a clay loam texture (44.1\% sand, $25.7 \%$ silt, $30.2 \%$ clay w/w), with $\mathrm{pH} 6.8$, ECC 19.8 meq $100 \mathrm{~g}^{-1}, 0.9 \mathrm{~g} \mathrm{~kg}^{-1}$ total $\mathrm{N}, 9$ $\mathrm{mg} \mathrm{P} \mathrm{kg}^{-1}, 111 \mathrm{mg} \mathrm{K} \mathrm{kg}^{-1}$, and organic matter $10 \mathrm{~g} \mathrm{~kg}^{-1}$.
Conventional tillage of the land was adopted, consisting in a primary tillage with a medium-depth moldboard (30 $\mathrm{cm}$ ) during the autumn prior to the experiments, followed by a secondary tillage in the spring with tandem disks and a smooth roller for the planting bed preparation. A local ecotype was used in this study. Single rhizomes (each one approximately $200 \mathrm{~g}$ with a minimum of one bud) of $A$. donax were planted at 13900 plants ha ${ }^{-1}$ in 0.90 m rows on 28 April and irrigated daily for the first week to encourage establishment, to increase availability of applied nutrients and to prevent wilting.

Treatments were arranged as a randomized complete block, strip-plot design with irrigation treatments as the main plot factor and pre-planting fertilization as the subplot factor. Irrigation treatments included no additional irrigation $\left(\mathrm{I}_{0}\right)$ and supplying $25 \% \mathrm{ET}_{0}$ water $\left(\mathrm{I}_{25}\right)$. Nitrogen treatments included no $\mathrm{N}$ supply $\left(\mathrm{N}_{0}\right)$ and $100 \mathrm{~kg} \mathrm{ha}^{-1}$ $\left(\mathrm{N}_{100}\right)$. All treatment combinations were replicated four times, and the sub-plot size was $47.5 \times 39.5 \mathrm{~m}$.

In the fertilized subplots, $\mathrm{N}$ was applied prior to planting to correct the low soil $\mathrm{N}$ content, using a 30-0-0 (urea ammonium nitrate) liquid fertilizer. Fertilizer was applied on the topsoil, and, to prevent ammonia losses from volatilization, it was immediately incorporated with a spike-tooth harrow. No post-emergence herbicide was applied to avoid detrimental responses affecting plant growth.

Weather data was collected with an automated weather station (Campbell Scientific, Logan, Utah, USA) located within $100 \mathrm{~m}$ of the experimental site. Pan evaporation was measured manually by means of a Class A evaporation pan and a hook gauge. Irrigation treatments were done monthly, from June to September. Treatments replaced $25 \% \mathrm{ET}_{0}$ lost from Class A pan evaporation of the previous interval.

\section{Biometric analysis}

Two whole plants from each experimental unit (subplot) were harvested every $15 \mathrm{~d}$ starting early July, for a total of nine harvests. Height, basal stem diameter and shoot number were recorded. The aerial portion was separated from the rhizome fraction in the field by cutting at ground level. Rhizome tissues were washed with water to remove soil. All tissues were dried separately $\left(72 \mathrm{~h}\right.$ at $\left.60{ }^{\circ} \mathrm{C}\right)$ and weighed. Samples from above-ground biomass were milled and subsequently analyzed to assess their chemical and technological characteristics (structural carbohydrates and lignin).

\section{Structural carbohydrates and lignin analysis}

Lignin and structural carbohydrates were quantified with standard biomass analytical methods provided by the National Renewable Energy Laboratory (Sluiter et al., 2008). The procedures use a two-step acid hydrolysis (in $72 \% \mathrm{H}_{2} \mathrm{SO}_{4}, 30.0 \pm 3{ }^{\circ} \mathrm{C}$ and incubation for $60 \pm 5 \mathrm{~min}$ ) to fractionate the biomass into monomeric, soluble forms. 
After completion of an autoclave cycle $\left(1 \mathrm{~h}\right.$ at $\left.121^{\circ} \mathrm{C}\right)$, samples were purified by reverse-phase HPLC operating at a wavelength of $320 \mathrm{~nm}$. An Aminex HPX-87H column (Bio-Rad, Richmond, California, USA) eluted at a flow rate of $0.6 \mathrm{~mL} \mathrm{~min}^{-1}$. The column was eluted with $0.005 \mathrm{M}$ sulfuric acid. The fractions corresponding to the elution volumes of glucans, xylans, arabinan, acetyls groups, residues, and other insoluble substance were collected separately. Acid soluble Klason lignin was quantified by UV-Vis spectroscopy, at $320 \mathrm{~nm}$ absorbance. Each sample was analyzed in triplicate.

\section{Statistical analysis}

Biometric and chemical component data were analyzed with linear mixed effects models. Irrigation and fertilization treatments represented fixed effects, whereas blocks and time were treated as random factors. The factorial experiment (Irrigation $\times$ Fertilization) was nested within each block, and time codes for repeated measurements made within each treatment plot within each block. Multiple comparisons tests to compare differences across treatment were conducted using Tukey's HSD post-hoc test $(\mathrm{P}<0.05)$. Above-ground dry biomass was related to a number of explanatory variables by multiple regression modeling.

A generalized additive model (GAM) was estimated to model the above-ground dry weight biomass accumulation, the independent response variable, in relation to continuous explanatory variables. The candidate variables were height, basal diameter, and number of stalks. Stepwise model selection was used to select which variables to keep in the model. Starting from a model with only linear contributions from the variables, stepwise selection drops or modifies smoothing parameters for one variable after the other, retaining the model showing the best reduction in deviance (Akaike information criterion, AIC). GAMs, proposed by Hastie and Tibshirani (1986), enabled biologists to model species responses to a wide range of data types under a single theoretical and computational framework (Yee and Mitchell, 1991). Non-parametric smoothers are used to describe the relationship (Wood, 2006).

Scatter plots of the above-ground fresh yield and dry yield $v s$. days after planting (DAP) indicated a strong nonlinear relationship. Furthermore, the data fit to a Sigmoid variable slope model (yield $(\mathrm{g})=\mathrm{Top} /$ $\left[1+10^{\wedge}\left\{\right.\right.$ Days $_{50}-$ DAP) Slope $\left.\left.\}\right]\right)$ where Top, Days ${ }_{50}$ and Slope are estimated model parameters. Days $s_{50}$ is the estimated DAP when yield $=50 \%$. The Slope parameter defines how rapidly biomass changes over time, with more positive values representing steeper slopes of the sigmoid curve.

A sum of squares reduction $F$-test was used to determine if treatments significantly affected biomass over time (Motulsky and Christopoulos, 2003). The F-test compared the sum of squares from a global model (all treatments share Top, Days $s_{50}$, and Slope values) against the cumulative sum of squares from models where Top, Days $_{50}$ and Slope values were determined separately for each treatment. If the sum of squares was significantly reduced $(\mathrm{P}<0.05)$ using separate parameter values, treatment effects were determined to be significant. Parameter estimates were used to calculate confidence intervals $(95 \%)$ for the number of DAP withheld until each treatment reached the arbitrary threshold of 750 g plant $^{-1}$ above-ground dry biomass (Motulsky and Christopoulos, 2003). Treatments were considered significantly different if their confidence intervals did not overlap. Nonlinear regression analysis of above-ground biomass data was performed using GraphPad Prism version 5.0a for Mac OS X, (GraphPad Software, La Jolla, California, USA).

All computations were performed with R 2.14.1 ( $\mathrm{R}$ Development Core Team, 2011), using the lme function of the R nlme package (Pinheiro et al., 2012), and R package $m g c v$ version 1.7-13 was used to produce the GAM (Wood, 2011), and ggplot2 (Wickham, 2009).

\section{RESULTS}

\section{Growth and biomass allocation}

Climate data recorded for the duration of the growing season showed a hot, dry summer, in which there were 35 consecutive days with no precipitation, and air temperatures that regularly exceeded $30{ }^{\circ} \mathrm{C}$ (data not shown). Arundo donax emergence started 7-10 DAP and new ramets continued to appear till the end of October, at which point the mean temperature dropped to $5{ }^{\circ} \mathrm{C}$. Weed infestation was minimal and scattered, generating very little competition on the crop. The principle species of weeds present included late spring emerging weeds, such as Amaranthus spp., Chenopodium spp., and Solanum nigrum L. In the non-irrigated treatment, some desiccation injury occurred toward the end of summer, inducing changes to phenology stages.

ANOVA indicated that rhizome sprouting, basal diameter, and height responded to irrigation ( $p<0.001)$, whereas fertilization as main factor was not significant (Table 1). The combination of irrigation and fertilization significantly influenced the average number of tillers present on each plant $(p<0.01)$, the greatest number of tillers being observed on those plants that were both irrigated and received $\mathrm{N}$ supplementation (16.3 tillers). Plants from the other treatment combinations presented between 10.1 and 12.0 tillers per plant $\left(\mathrm{N}_{100}\right.$ and $\mathrm{N}_{0}+\mathrm{I}_{25}$, respectively; data not shown). Tiller production was fairly constant throughout the period considered, as confirmed by an absence of interaction with time as random effect. On the contrary, both average basal diameter and height were found to be significantly affected by time ( $\mathrm{p}<0.01$ and $\mathrm{p}<0.001$, respectively; data not shown). Height was also affected by irrigation by time interaction $(\mathrm{p}<0.001)$. From early July, no change in basal 
Table 1. Results of mixed model analyses of the effects of irrigation, fertilization, and their interaction on biometric traits and solid dry composition. The values used in the analysis were block means $(n=4)$. Values in the table are probabilities for a fixed effect.

\begin{tabular}{lccc}
\hline Dependent variable & Irrigation $(\mathrm{I})$ & Fertilization $(\mathrm{F})$ & $\mathrm{I} \times \mathrm{F}$ \\
Parameters & $* * *$ & $\mathrm{~ns}$ & $*$ \\
\hline Above-ground fresh weight & $* * *$ & $\mathrm{~ns}$ & $* *$ \\
Above-ground dry weight & $* *$ & $\mathrm{~ns}$ & $\mathrm{~ns}$ \\
Dry matter & $* * *$ & $\mathrm{~ns}$ & $* *$ \\
Stalks number & $* * *$ & $\mathrm{~ns}$ & $\mathrm{~ns}$ \\
Height & $* * *$ & $\mathrm{~ns}$ & $\mathrm{~ns}$ \\
Basal diameter & $* * *$ & $\mathrm{~ns}$ & $\mathrm{~ns}$ \\
Rhizome fresh weight & $* * *$ & $\mathrm{~ns}$ & $\mathrm{~ns}$ \\
Rhizome dry weight & $\mathrm{ns}$ & $\mathrm{ns}$ & $\mathrm{ns}$ \\
Rhizome/epigeal dry weight ratio & $\mathrm{ns}$ & $\mathrm{ns}$ & $\mathrm{ns}$ \\
Glucans & $\mathrm{ns}$ & $\mathrm{ns}$ & $\mathrm{ns}$ \\
Xylans & $\mathrm{ns}$ & $\mathrm{ns}$ & $\mathrm{ns}$ \\
Arabinan & $\mathrm{ns}$ & $\mathrm{ns}$ & $\mathrm{ns}$ \\
Acetyl groups & $\mathrm{ns}$ & $\mathrm{ns}$ & $\mathrm{ns}$ \\
Klason lignin & $\mathrm{ns}$ & $\mathrm{ns}$ & $\mathrm{ns}$ \\
Residues & $\mathrm{ns}$ & $\mathrm{ns}$ & $\mathrm{ns}$ \\
Others & $\mathrm{ns}$ & $\mathrm{ns}$ & $\mathrm{ns}$ \\
Ashes & & & \\
\hline
\end{tabular}

*Significantly different at the 0.05 probability level.

${ }^{* *}$ Significantly different at the 0.01 probability level.

****Significantly different at the 0.001 probability level.

ns: non significant at the 0.05 probability level.

diameter was observed in absence of irrigation, with the average being $11.9 \mathrm{~mm}$ (data not shown). Among the irrigated plants, a pronounced increase in diameter was evident from the beginning of August, and by the end of the growing season, average basal diameter reached 14.2 $\mathrm{mm}$. In our study, a considerable difference in average stem height was detected in the presence of supplemental irrigation, resulting in a $46 \%$ increase over the control (176.3 vs. $257.6 \mathrm{~cm}$ at the end of the growing season; data not shown). In the absence of irrigation, an overall lack of vigor was evident starting from the end of September.

A generalized additive model was selected in this study to explore how above-ground dry weight, the response variable, responded to the contribution of a variety of explanatory variables. Basal stalk diameter was not included in the final GAM model presented here, as it proved to be a weak and not significant explanatory variable. The summary of this GAM shows highly significant terms for both smoothed terms: the effect of height, s(height), on 6.55 estimated degrees of freedom, and the number of stalks, s(stalks), on 3.41 estimated degrees of freedom (Figure 1). The model explains $88.7 \%$ of the deviance in above-ground biomass. The vertical axes express the influence of each variable on the prediction. The response curves shows that height plays a considerable role in determining dry weight, while the number of stocks is only slightly influential.

Stepwise multiple linear regression was performed to quantify the relationship among crop variables and to predict above-ground dry weight. Multiple regression analyses associated dry weight as a response variable to average height and numbers of stalks as explanatory variables, using the following model $\left(R^{2}=0.96, \mathrm{p}<\right.$ $0.001): \mathrm{dw}=(8.34) \mathrm{h}+(45.4) \mathrm{nsh}-1171.4$, where $\mathrm{dw}$ is dry weight $(\mathrm{g})$, $\mathrm{h}$ is average plant height $(\mathrm{cm})$, and $\mathrm{nsh}$ is number of shoots per plant. For the multiple regression equation, residuals from regression were plotted in relation to predicted and observed variables to ensure that error variances were homogeneous and that no evidence existed for lack of fit of data to the regression equation, as well as whether there was systematic over- or underprediction in specific ranges of data (Figure 2).

Analysis of the above-ground biomass data revealed a significant irrigation $\times$ fertilization treatment interaction (Table 1). Following from that, subsequent data were analyzed in treatment combinations. Treatments significantly affected above-ground dry yield during the establishment year in the present study (Table 2). The sigmoid model used to predict above-ground dry yields (Figure 3A) provided a good fit of the aerial biomass data, resulting in average $\mathrm{R}^{2}$ values of 0.96 dry biomass (Table 3 ).

$\mathrm{N}_{100}+\mathrm{I}_{25}$ was the treatment that produced the highest fresh biomass potential $\left(4444 \mathrm{~g} \mathrm{plant}^{-1}\right)$, followed closely by $\mathrm{N}_{0}+\mathrm{I}_{25}$ (4002 g plant $^{-1}$; data not shown). In the absence of irrigation, the addition of $\mathrm{N}$ was detrimental, resulting in a lower fresh biomass potential $\left(1291 \mathrm{~g} \mathrm{plant}^{-1}\right)$. The results of the predicted dry weight biomass highlight the significant response to irrigation treatment $(+97 \%$ on average), which agree with the results found for fresh
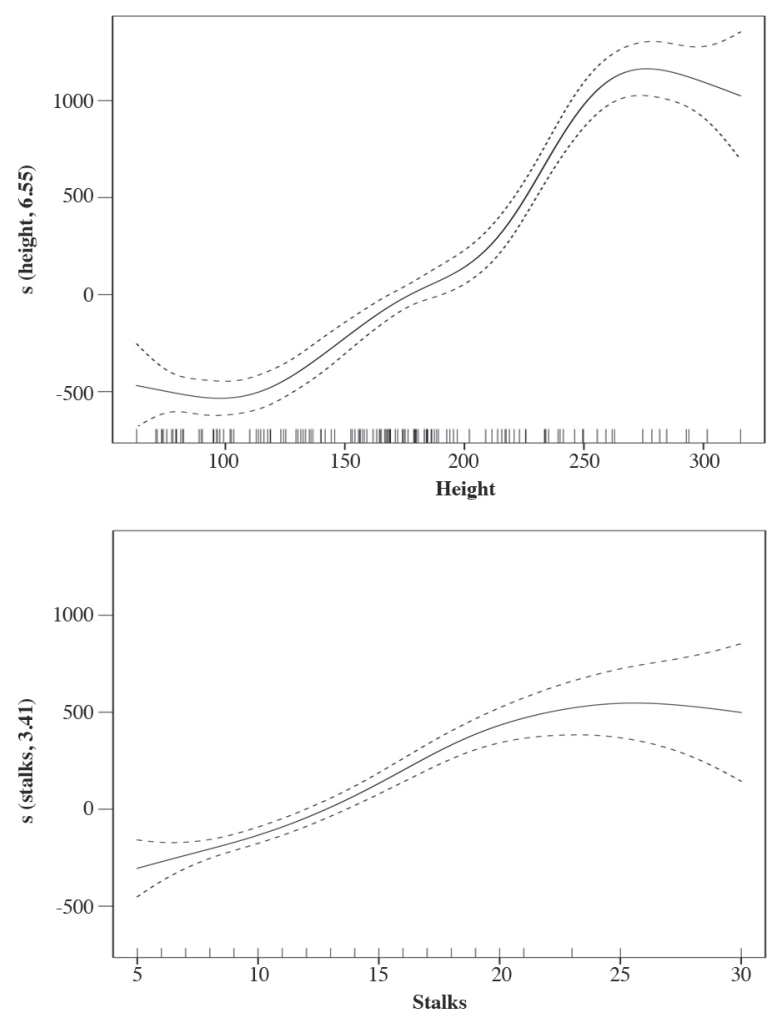

Figure 1. Response curves of above-ground dry weight to the predictor variables in the generalized additive model (GAM) analysis. The distribution of data is indicated by the vertical marks along the $x$-axis (rug plot). Confidence intervals at $95 \%$ are shown by dotted lines. 


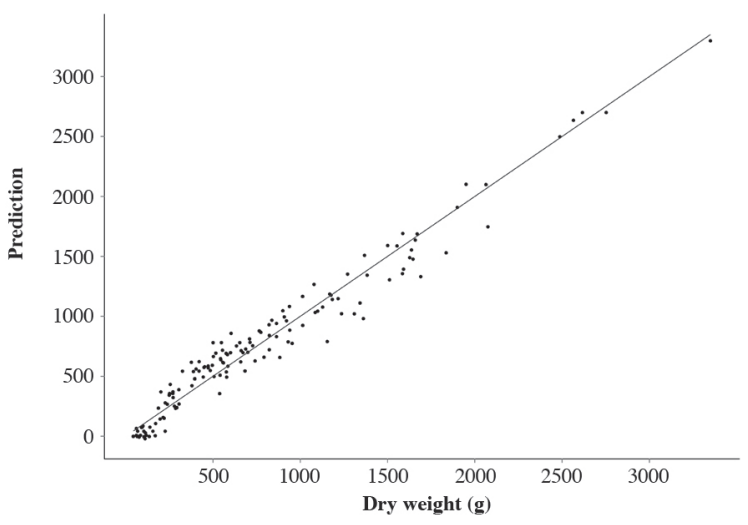

Figure 2. Plot prediction of above-ground dry weight against true response. Multiple regression analyses associated Arundo donax biomass with height and number of shoots, using the following model: $\mathrm{dw}=(\mathbf{8 . 3 4}) \mathrm{h}+(\mathbf{4 5 . 4}) \mathrm{nsh}-\mathbf{1 1 7 1 . 4}$, where $\mathrm{dw}=$ dry weight $(\mathrm{g})$, $\mathrm{h}=$ average plant height $(\mathrm{cm})$, and $\mathrm{nsh}=$ number of shoots per plant.

Table 2. Hypothesis test summaries for the effect of treatment in Giant reed (Arundo donax) on above-ground dry yield during the establishment year.

\begin{tabular}{lc}
\hline Sum of squares reduction test & \multicolumn{1}{c}{ Dry yield } \\
\hline Null hypothesis & \multicolumn{1}{c}{$\begin{array}{l}\text { Shared regression parameters (Top, Days }{ }_{50}, \\
\text { and Slope) }\end{array}$} \\
Alternative hypothesis & Three parameters different for each data set \\
Numerator df & 9 \\
Denominator df & 228 \\
$F$-value & 135.2 \\
$P$-value & $<0.001$ \\
\hline
\end{tabular}
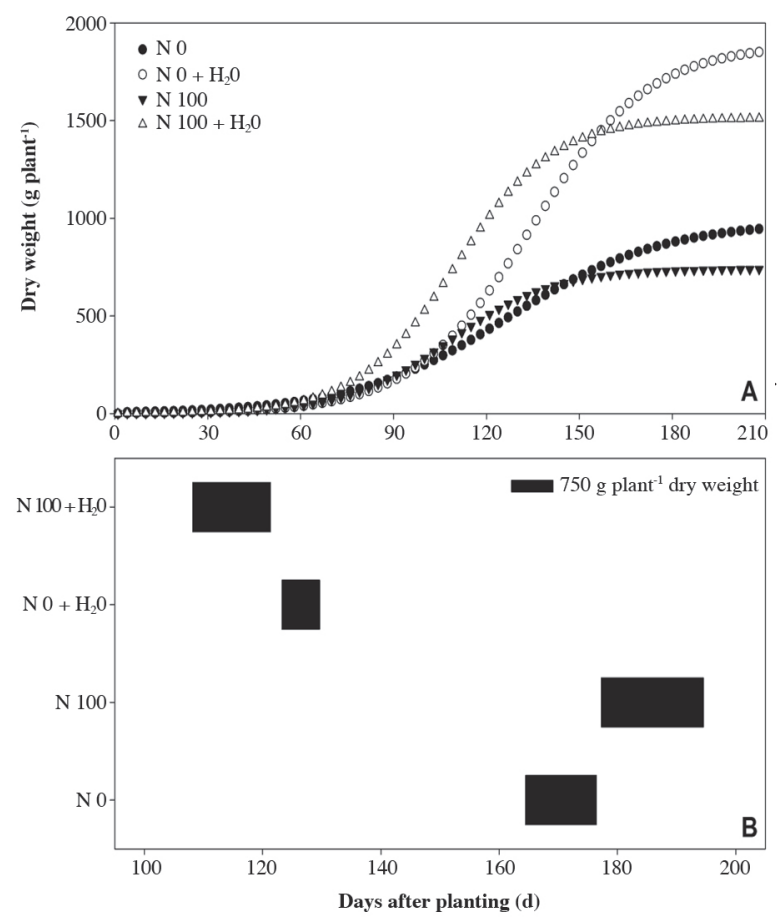

Figure 3. (A) Predicted above-ground dry yield curves for Arundo donax in the establishment year. (B) The $95 \%$ confidence intervals for the number of days after planting until entries reached $750 \mathrm{~g}$ plant $^{-1} \mathrm{DM}$ in the establishment year. Entries with overlapping bars were not significantly different $(\mathrm{P}<0.05)$.
Table 3. Statistical parameters for predicting above-ground dry yields of Arundo donax with different agronomic regimes in the establishment year.

\begin{tabular}{lrcccccc}
\hline Treatment & Top & $\mathrm{SE}^{\dagger}$ & Days $_{50}$ & $\mathrm{SE}^{\ddagger}$ & Slope & $\mathrm{SE}^{\S}$ & $\mathrm{R}^{2}$ \\
\hline $\mathrm{N}_{0}$ & 982 & 52.5 & 126.8 & 4.61 & 0.017 & 0.002 & 0.93 \\
$\mathrm{~N}_{0}+\mathrm{H}_{2} \mathrm{O}$ & 1890 & 54.7 & 134.2 & 2.14 & 0.023 & 0.002 & 0.97 \\
$\mathrm{~N}_{100}$ & 741 & 13.9 & 107.9 & 1.62 & 0.026 & 0.002 & 0.98 \\
$\mathrm{~N}_{100}+\mathrm{H}_{2} \mathrm{O}$ & 1514 & 39.4 & 109.9 & 2.18 & 0.028 & 0.003 & 0.95 \\
\hline
\end{tabular}

${ }^{\top}$ Standard error of Top.

Standard error of Days 50.

\$Standard error of Slope.

$\mathrm{N}$, the above-ground dry biomass was significantly lower (1514 vs. $\left.1890 \mathrm{~g} \mathrm{plant}^{-1}\right)$. Confidence intervals (95\%) of the mean DAP to reach $750 \mathrm{~g}$ plant $^{-1}$ above-ground dry biomass for each combination of treatments are illustrated in Figure 3B. Treatments with non-overlapping confidence interval bars are significantly different $(P=0.05)$. The DAP needed to reach the prefixed threshold of dry aboveground biomass was significantly greater for the non irrigated thesis. When plants were irrigated and fertilized with $\mathrm{N}$, giant reed reached 750 g plant $^{-1}$ dry biomass 71.2 $\mathrm{d}$ sooner than the slowest treatment combination, $\mathrm{N}_{100}$. Above-ground DM concentration strongly correlated with date ( $p<0.001$ ), and it varied from $35.8 \%$ to $49.4 \%$ (August and November, respectively). With regard to the treatments, irrigation led to a minimal but none the less significant detrimental variation $(-3 \%)$ in comparison to dry treatments.

Regarding rhizome growth, both fresh and dry weight were significantly enhanced by irrigation $(\mathrm{p}<0.001)$, as well as by an irrigation by time interaction. Similar to previous above-ground parameters, a gradual but significant lower response on both variables was observed in the driest plot, in particular from early September onward. The rhizome/ epigeal dry weight ratio was not significantly affected by treatments. It exhibited a steady decline till early August, but it significantly improved through the experiment time from 0.36 to 0.76 (data not shown).

\section{Solid dry composition}

Inspection of the chemical composition of A. donax, expressed as \% w/w of solid DM, revealed that the quality composition of its above-ground biomass was not affected by the different treatment combinations, although significant differences were observed in connection with the progression of the maturity stages (Figure 4), as was expected. The hemicellulosic fraction was consistently present from an early stage, and ranged from $48 \%$ to $57 \%$ at the end of growing season. The most abundant fractions detected were glucans and xylans. As time went by, the relative proportion of these two polysaccharides increased, although xylans to a lesser degree. The arabinan fraction, representing $2 \%$ of the total DM, remained very constant throughout. Xylans from graminaceous plants contain 0 -acetyl groups, and their content slightly increased over time. Above-ground cellulosic raw material became more lignified during 


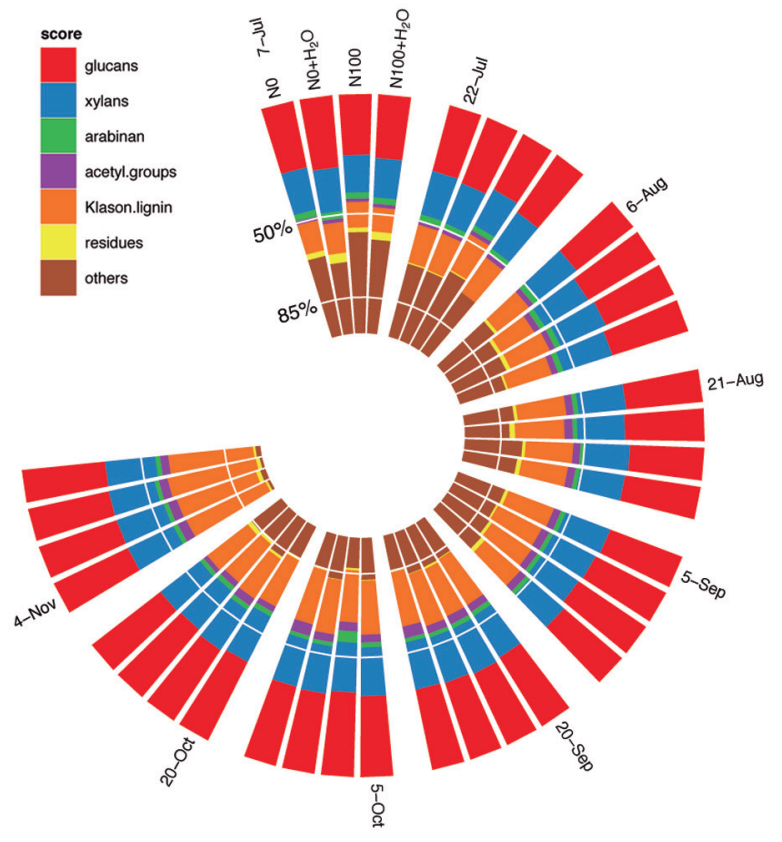

Figure 4. Solid dry composition of Arundo donax lignocellulosic biomass as a function of agronomic factors for duration of the experiment.

the course of the experiment. The percentage of lignin increased gradually from $12 \%$ to $22 \%$ until October, then sharply rose during the final part of the end of the growing season, when it attained $36 \% \mathrm{w} / \mathrm{w}$ of solid dry composition. Variations in ash content found at different maturity stages were significant, but were not affected by treatments. The quantity decreased remarkably at senescence (from $10.7 \%$ to $3.6 \%$ in July and November, respectively; data not shown).

\section{DISCUSSION}

Despite increasing interest in A. donax as a bioenergy feedstock for use in combustion (Nassi o Di Nasso et al., 2010), this study focused on its potential as a lignocellulosic ethanol feedstock. From an industrial point of view, it is necessary to specify the planned use, as this will determine which qualities are desirable in the biomass. Important quality traits for lignocellulosic ethanol, e.g. carbohydrate content, are not as important for crops intended for combustion, for which the lignin content is more critical. In this study, the plasticity of this caespitose $\mathrm{C}_{3}$ perennial grass in response to different resource availability was evaluated specifically with bioethanol production in mind. It is important to mention that the results reported here are inevitably influenced by the biomass unit - the whole plant - for which our biometric and chemical analysis are reported, mainly as a result of heterogeneous growth due to clonal sprouting, but also because chemical composition is known to be affected by tissue age (Joseleau and Barnoud, 1975).

Generalized additive model is a powerful tool to proceed from the description of response curves of perennial species to environmental gradients toward the spatial predictions of these same species distribution under changing environmental conditions. For a wide range of regimes, the GAM model confirmed that the strong allometric relationship between ramet height and aboveground dry biomass production is valid, whereas basal diameter is not related. This result is in agreement with a previous study conducted on a spontaneous population of a different age, where individual stem height was found to be the best predictive parameter for estimating shoot dry weight (Spencer et al., 2006). The equation obtained using the model successfully explained a high proportion of total variation in above-ground dry weight, using few, easy to determine biometric parameters.

Tiller recruitment occurred from extended rhizomes, producing spaced orthotropic culms, and the species exhibited a competitive ability against weeds, as confirmed by growth analysis. The DM production showed an exponential growth rate till the end of summer, but decreased in the autumn as a result of leaf blade and sheath senescence. The rhizome biomass however, continued to increase during that period, due to higher rate of photosynthate translocation and phloem transport. The biomass allocation between canopy and rhizome structure followed a seasonal pattern, as did variations in chemical composition. During the months of peak biomass growth, giant reed allocated relatively more DM to its stems. The differences observed in above-ground biomass between treatments are ascribed to differences in water availability and reflect allocation pattern in rhizomes biomass.

From an early stage, biometric parameters, as well as above- and below-ground growth were directly related to the irrigation treatment, whereas $\mathrm{N}$ fertilization was not significant for all parameters analyzed in the present study. An arbitrary threshold for comparing dry biomass accumulation between treatments was set at $750 \mathrm{~g}$ plant $^{-1}$, and based on this criterion; irrigation appreciably increased the response, whereas $\mathrm{N}$ fertilization had a moderate and inconsistent effect. Differences as much as $1149 \mathrm{~g} \mathrm{DM}_{\text {plant }}^{-1}$ were observed between treatments following the onset of drought stress symptoms. This could have a significant impact on supplemental irrigation requirements over an entire growing season, especially in dry regions. Our results confirmed that plants in watersufficient environments show higher productivity. Also they conserve nutrients more efficiently, by developing an extensive underground rhizomatous system with short internodes. When A. donax adapts to changing resource availability, it may alter reserve allocation priorities and affect canopy productivity. Studies conducted on the effect of $\mathrm{N}$ input on perennial energy crops have obtained contradictory results. With specific regard to giant reed, 
experiments have been conducted under a wide range of conditions, both in short and long term, with organic and inorganic fertilizers, in experimental plots as well as natural riparian habitats (Angelini et al., 2005; Quinn et al., 2007; Mantineo et al., 2009; Smith and Slater, 2010). In watershed areas, established populations of giant reed exhibit seasonal patterns of recruitment but no dormancy in the presence of high $\mathrm{N}$ availability in the soil (Decruyenaere and Holt, 2005). A positive effect of $\mathrm{N}$ fertilization on above-ground biomass, does not necessarily justify its systematic use. Reducing energyintensive inputs in the production process improves efficiency, a key point for energy crops. In agreement with Rossa et al. (1998), our data confirm that $A$. donax is characterized by an efficient photosynthetic system that enhances the use efficiency of resources, particularly water. The primary perennating organ, the rhizome, acts alternatively as a source and sink of both $\mathrm{N}$ and $\mathrm{C}$, and it optimizes nutrient recycling within the system. Arundo donax does not direct address energy to seed production. Our results clearly demonstrate that supplemental irrigation has a significant impact on yield in the establishment year. An onset of summer dormancy was clearly observed during long-term drought stress, with a particularly strong impact on fresh yield.

Overall composition quality improves during senescence, when canopy biomass dries 'on the stem'. Differences in the concentrations of specific components were not detected in relation to the main treatments. However, variability in chemical composition was clearly related to different maturity stages, as highlighted by chemical analysis of number of macromolecules, glucans and lignin in particular. In agreement with previous studies (Neto et al., 1997; Seca et al., 2000), analysis conducted on whole plants confirmed that xylan content was not affected by tissue age and the average degree of polymerization increases with maturity. In addition, ash analysis revealed a dilution effect over time, apparently due to the concomitant phloem translocation to the perennial organ.

Given the complex composition of lignocellulosic biomass, a wide spectrum of reactive platform chemicals are proposed as an alternative to petroleum-derived chemicals, and the biorefineries allowed are wider than petroleum refineries (Cherubini and Strømman, 2011). For example, xylose is a major source of pentosans for the furfural-based industry, used for a wide range of applications in oil refining, plastics, pharmaceutical and agrochemical industries (Mamman et al., 2008). From the process application standpoint, these results indicate that A. donax crops specifically dedicated to lignocellulosic ethanol should be assisted with irrigation in the establishment year to reduce early growth lag. Also, the best time to harvest is after the onset of senescence in order to reduce mineral removal from the soil and maximize carbohydrate content.

\section{CONCLUSIONS}

Although Arundo donax is known as a plant that doesn't respond to fertilizer and water in established crop stands, this study suggests that a positive increase in its growth in the establishment year may be achieved by a modest but proper use of the irrigation. As the goals of sustainability evolve from maximizing crop yields, to early achieving economic optima, A. donax is gaining value as a lowinput, sustainable perennial grass for the Mediterranean area with many potential uses as a primary lignocellulosic feedstock for the production of energy, fuels, and chemicals.

\section{ACKNOWLEDGEMENTS}

The authors are extremely grateful to Dr. Chiara Tardioli for providing constructive informatics advice. We thank Mr. Enrico and Michele Colla for their technical and logistic support. This research was funded through a research contract between the University of Pisa Department of Agriculture, Food and Environment, and Chemtex Italia S.r.l., Tortona (Italy).

\section{LITERATURE CITED}

Angelini, L.G., L. Ceccarini, and E. Bonari. 2005. Biomass yield and energy balance of giant reed (Arundo donax L.) cropped in central Italy as related to different management practices. European Journal of Agronomy 22:375-389. doi:10.1016/J.Eja.2004.05.004.

Barney, J.N., and J.M. Ditomaso. 2008. Nonnative species and bioenergy: Are we cultivating the next invader? BioScience 58:64-70. doi:10.1641/b580111.

Boose, A.B., and J.S. Holt. 1999. Environmental effects on asexual reproduction in Arundo donax. Weed Research 39:117-127.

Cherubini, F., and A.H. Strømman. 2011. Chemicals from lignocellulosic biomass: Opportunities, perspectives, and potential of biorefinery systems. Biofuels, Bioproducts and Biorefining 5:548-561. doi:10.1002/bbb.297.

Decruyenaere, J., and J. Holt. 2005. Ramet demography of a clonal invader, Arundo donax (Poaceae), in Southern California. Plant and Soil 277:41-52. doi:10.1007/s11104-005-0264-5.

Hastie, T., and R. Tibshirani. 1986. Generalized additive models. Statistical Science 1:297-310.

Jordan, N., G. Boody, W. Broussard, J.D. Glover, D. Keeney, B.H. McCown, et al. 2007. Sustainable development of the agricultural bio-economy. Science 316:1570-1571. doi:10.1126/ science. 1141700 .

Joseleau, J.P., and F. Barnoud. 1975. Hemicelluloses of Arundo donax at different stages of maturity. Phytochemistry 14:71-75.

Lewandowski, I., J.M.O. Scurlock, E. Lindvall, and M. Christou. 2003. The development and current status of perennial rhizomatous grasses as energy crops in the US and Europe. Biomass and Bioenergy 25:335-361. doi:10.1016/S09619534(03)00030-8.

Mack, R.N. 2008. Evaluating the credits and debits of a proposed biofuel species: Giant reed (Arundo donax). Weed Science $56: 883-888$

Mamman, A.S., J.-M. Lee, Y.-C. Kim, I.T. Hwang, N.-J. Park, Y.K. Hwang, et al. 2008. Furfural: Hemicellulose/xylose derived biochemical. Biofuels, Bioproducts and Biorefining 2:438-454. doi:10.1002/bbb.95. 
Mantineo, M., G.M. D’Agosta, V. Copani, C. Patane, and S.L. Cosentino. 2009. Biomass yield and energy balance of three perennial crops for energy use in the semi-arid Mediterranean environment. Field Crop Research 114:204-213. doi:10.1016/J. Fcr.2009.07.020

Monti, A., and A. Zatta. 2009. Root distribution and soil moisture retrieval in perennial and annual energy crops in Northern Italy. Agriculture, Ecosystems \& Environment 132:252-259. doi:10.1016/J.Agee.2009.04.007.

Motulsky, H., and A. Christopoulos. 2003. Fitting models to biological data using linear and nonlinear regression: A practical guide to curve fitting. GraphPad Software, Inc., San Diego, California, USA.

Muchow, R.C., and R. Davis. 1988. Effect of nitrogen supply on the comparative productivity of maize and sorghum in a semiarid tropical environment. II. Radiation interception and biomass accumulation. Field Crop Research 18:17-30. doi:10.1016/03784290(88)90056-1.

Nassi o Di Nasso, N., L.G. Angelini, and E. Bonari. 2010. Influence of fertilisation and harvest time on fuel quality of giant reed (Arundo donax L.) in central Italy. European Journal of Agronomy 32:219-227.

Neto, C.P., A. Seca, A.M. Nunes, M.A. Coimbra, F. Domingues, D. Evtuguin, et al. 1997. Variations in chemical composition and structure of macromolecular components in different morphological regions and maturity stages of Arundo donax. Industrial Crop and Products 6:51-58.

Pinheiro, J., D. Bates, S. DebRoy, D. Sarkar, and R.D.C. Team. 2012. nlme: Linear and nonlinear mixed effects models. $\mathrm{R}$ package version 3.1-103.

Quinn, L.D., M.A. Rauterkus, and J.S. Holt. 2007. Effects of nitrogen enrichment and competition on growth and spread of giant reed (Arundo donax). Weed Science 55:319-326. doi:10.1614/Ws-06139.1

R Development Core Team. 2011. R: a language and environment for statistical computing. R Foundation for Statistical Computing, Vienna, Austria.

Riffaldi, R., A. Saviozzi, R. Cardelli, F. Bulleri, and L. Angelini. 2010. Comparison of soil organic-matter characteristics under the energy crop giant reed, cropping sequence and natural grass. Communications in Soil Science and Plant Analysis 41:173-180. doi: $10.1080 / 00103620903426972$.
Rossa, B., A.V. Tuffers, G. Naidoo, and D.J. von Willert. 1998 Arundo donax L. (Poaceae) - a C3 species with unusually high photosynthetic capacity. Botanica Acta 111:216-221.

Schmer, M.R., K.P. Vogel, R.B. Mitchell, B.S. Dien, H.G. Jung, and M.D. Casler. 2012. Temporal and spatial variation in switchgrass biomass composition and theoretical ethanol yield. Agronomy Journal 104:54-64. doi:10.2134/agronj2011.0195.

Seca, A.M.L., J.A.S. Cavaleiro, F.M.J. Domingues, A.J.D. Silvestre, D. Evtuguin, and C.P. Neto. 2000. Structural characterization of the lignin from the nodes and internodes of Arundo donax reed. Journal of Agricultural and Food Chemistry 48:817-824.

Sluiter, A., B. Hames, R. Ruiz, C. Scarlata, J. Sluiter, D. Templeton, et al. 2008. Determination of structural carbohydrates and lignin in biomass [electronic resource]: laboratory analytical procedure (LAP) National Renewable Energy Laboratory, Golden, Colorado, USA.

Smith, R., and F.M. Slater. 2010. The effects of organic and inorganic fertilizer applications to Miscanthus $x$ giganteus, Arundo donax and Phalaris arundinacea, when grown as energy crops in Wales, UK. Gcb Bioenergy 2:169-179. doi:10.1111/J.17571707.2010.01051.X

Spencer, D.F., P.S. Liow, W.K. Chan, G.G. Ksander, and K.D Getsinger. 2006. Estimating Arundo donax shoot biomass. Aquatic Botany 84:272-276. doi:10.1016/J.Aquabot.2005.11.004.

Wickham, H. 2009. ggplot2: Elegant graphics for data analysis Springer, New York, USA.

Wood, S.N. 2006. Generalized Additive Models: an introduction with R. Chapman \& Hall/CRC, Boca Raton, Florida, USA.

Wood, S.N. 2011. Fast stable restricted maximum likelihood and marginal likelihood estimation of semiparametric generalized linear models. Journal of the Royal Statistical Society: Series B (Statistical Methodology) 73:3-36. doi:10.1111/j.14679868.2010.00749.x.

Yee, T.W., and N.D. Mitchell. 1991. Generalized Additive Models in plant ecology. Journal of Vegetation Science 2:587-602. 